\title{
Vascular Shutdown and Pro-inflammatory Cytokine Expression in Breast Cancer Tumors after Photodynamic Therapy Mediated by Nano-sized Liposomes Containing Aluminium-Chloride-Phthalocyanine
}

Maite Cevallos Mijan ${ }^{1}$, João Paulo Figueiró Longo ${ }^{1 *}$, Larissa Naves Duarte de Melo', Andreza Ribeiro Simioni ${ }^{2}$, Antônio Cláudio Tedesco ${ }^{2}$ and Ricardo Bentes Azevedo ${ }^{1 *}$

${ }^{1}$ Department of Genetics and Morphology, Institute of Biological Sciences, University of Brasilia, Brasilia, Brazil

${ }^{2}$ Laboratory of Photobiology and Photomedicine, Department of Chemistry, University of São Paulo, Ribeirão Preto, Brazil

\begin{abstract}
Breast cancer is the most prevalent solid tumor worldwide, being the second most common cause of death in women. Treatments recommended for breast cancer include both local and regional protocols such as surgery and radiotherapy, and systemic procedures, such as chemotherapy and hormonal therapies. In most of them, there is much functional impairment and low selectivity for tumor, leading to immunosuppression. Alternatively, some new protocols such as Photodynamic therapy (PDT) has been proposed as a therapeutic option for breast cancer management. One of the promising features related to PDT is immune activation against tumor cells. Thus, considering the importance of immunological activation against tumor cells after PDT, the aim of this study was to evaluate the expression of local and systemic inflammatory cytokines in breast cancer-bearing mice after PDT application, mediated by the photosensitizer aluminium-chlorine-phtalocyanine (AICIPc) in liposomal formulation (Lipo-AICIPc). In addition, we evaluate the efficacy of this PDT protocol in the treatment of murine mammary carcinoma cell line $-4 \mathrm{~T} 1$ in in vitro and in vivo experimental models. It could be observed in the present study that PDT mediated by local application of Lipo- AICIPc in the treatment of breast cancer in Balb / c mice acted by multiple mechanisms, including the induction of cell death by necrosis and due to direct oxidative damage to tumor cells and vascular shutdown. All these events contributed to the expression of inflammatory cytokines, resulting in a subsequent anti-tumor inflammatory response. In conclusion, PDT mediated by Lipo-AICIPc is capable of activating an inflammatory response, providing support to be used at least as an adjunct therapy to surgical treatments, allowing greater tumor control for long periods and, possibly, greater control of metastatic foci.
\end{abstract}

Keywords: Breast cancer; Liposomes; Nanoparticles; Tumors; Cytokine Expression; Vascular shutdown

\section{Introduction}

Breast cancer is the most prevalent solid tumor worldwide, and it has been the most commonly diagnosed malignancy in women since the 1990s, being the second most common cause of death in women [1]. Around $20 \%$ of patients with early-stage breast cancer develop metastases within five years after the initial diagnosis. The survival of these patients varies significantly, with median of nine months to three years [2]. The treatments recommended for breast cancer include both local and regional protocols such as surgery and radiotherapy, and systemic procedures, such as chemotherapy and hormonal therapies. In most of them, there is much functional impairment and low selectivity for tumor, leading to immunosuppression and clinical signs of weakness, which limit the therapeutic outcomes $[3,4]$

In order to minimize the side effects, Photodynamic Therapy (PDT) has been proposed as a therapeutic option for breast cancer management $[5,6]$. PDT is clinically approved, and widely used for malignant and nonmalignant lesions in various locations, such as skin, head and neck, and esophagus. For breast cancer, the literature presents the usefulness of PDT in different reports involving in vitro $[7,8]$, preclinical $[9,10]$, and even clinical reports with the treatment of recurrent and metastatic lesions [11], describing PDT as useful tool for breast cancer management.

PDT requires the action of three main components: (I) photosensitizer drugs; (II) harmless light in specific wavelengths; and (III) molecular oxygen. The mechanism involves photosensitizer (PS) light exposure that promotes an increase in PS energy levels to an excited singlet state. This excited PS form can return to its ground state by fluorescence emission, or, alternatively, undergoes intersystem crossover to a more stable triplet excited state. The excited triplet state can react with cellular substrate, in a Type I reaction, producing different types of adducts and reactive species; or the excited triplet PS can transfer its energy to molecular oxygen, in a Type II reaction, producing highly reactive oxygen species (ROS), such as singlet oxygen. This photochemical translation, light energy translated to ROS production, will promote extensive disruption of biomolecules and cell death in target cells [12].

The massive generation of ROS triggers several cellular mechanisms that directly induce cell death through different pathways: apoptosis, necrosis and/or autophagy. Cell death pathway depends on different factors, such as: cell type; concentration of photosensitizer; amount of energy; and intracellular localization of the photosensitizer [13]. Along

*Corresponding authors: João Paulo Figueiró Longo, Department of Genetics and Morphology, Institute of Biological Sciences, University of Brasília, Brasilia, Brazil, Tel: 5561 3107-3087; Fax: +55 61 3107-2923; E-mail: jplongo82@gmail.com

Ricardo Bentes Azevedo, Department of Genetics and Morphology, Institute of Biological Sciences, University of Brasília, Brasilia, Brazil, Tel: 5561 3107-3087 Fax: +5561 3107-2923; E-mail: razevedo@unb.br

Received June 03, 2014; Accepted August 20, 2014; Published August 27, 2014

Citation: Mijan MC, Longo JPF, Melo LND, Simioni AR, Tedesco AC, et al (2014) Vascular Shutdown and Pro-inflammatory Cytokine Expression in Breast Cancer Tumors after Photodynamic Therapy Mediated by Nano-sized Liposomes Containing Aluminium-Chloride-Phthalocyanine. J Nanomed Nanotechnol 5: 218. doi: 10.4172/2157-7439.1000218

Copyright: @ 2014 Mijan MC, et al. This is an open-access article distributed under the terms of the Creative Commons Attribution License, which permits unrestricted use, distribution, and reproduction in any medium, provided the original author and source are credited. 
with direct cell death, PDT mechanisms include an extensive vascular shutdown, which reduces the nutrient supply and oxygen tension in the treated tissues, leading to a massive secondary necrosis. In addition to that, the oxidative stress produced during PDT leads to the release of highly immunogenic molecules, such as heat shock proteins and damage-associated molecular patterns that stimulate a specific immune response against the cancer cells [14].

This third antitumor mechanism involves a drastic change in tumor vasculature, which becomes permeable to blood proteins and proinflammatory cells. These pro-inflammatory cells quickly and massively invade the tumor after PDT. The immune cells attracted by released immunogenic molecules and other pro-inflammatory mediators act by removing tissue debris, including dead and injured cells. In addition to that, various cytokines involved in regulating the inflammatory process are expressed in the tumor microenvironment. Among the most commonly encountered include the IL- $1 \beta$, IL- 6 , TNF- $\alpha$ and TGF- $\beta$, being co-responsible for the induction and maintenance of acute inflammatory response after PDT $[14,15]$.

Our research group has published some reports using AluminiumChloride-Phtalocyanine (AlClPc) entrapped in nano-sized liposomes as a PS system to treat tumor or bacteria cells in in vitro $[7,16]$, in vivo $[17,18]$, and clinical studies [19]. In our experience with this nanobased PS carrier (Lipo-AlClPc), we have observed the effectiveness of PDT in destroying the target cells, shutting down tumor vessels, and forming a massive presence of inflammatory cells in tumor tissues treated with this PDT protocol. The nanoscopic characterization of this nano-sized liposome has previously been published. The vesicles have an average size of $220 \mathrm{~nm}$ in a unimodal size distribution, with a polydispersity index of 0.25 [17].

Therefore, considering the three main anti-tumor effects related to PDT: (1) direct cell death; (2) tumor vascular shutdown; and (3) immune system activation, the first two have previously been investigated and were presented in our previous reports and in the results section of the present article. However, the investigation of the immune system activation after PDT mediated by Lipo-AlClPc has not been investigated until now. Thus, considering the importance of immunological activation against tumor cells after PDT, the aim of this study was to evaluate the expression of local and systemic inflammatory cytokines in breast cancer-bearing mice after PDT application, mediated by Lipo-AlClPc. In addition, we evaluate the efficacy of this PDT protocol in the treatment of murine mammary carcinoma cell line - 4T1 in in vitro and in vivo experimental models.

\section{Material and Methods}

\section{In vitro study}

Cell culture and liposome preparation: Murine breast cancer cell line 4T1 was purchased from American Type Cell Collection. 4T1 cells were routinely maintained in culture flasks (TPP, Switzerland), at $37^{\circ} \mathrm{C}$ in $5 \% \mathrm{CO}_{2}$, in DMEM with $100 \mathrm{IU} / \mathrm{mL}$ penicillin and $100 \mu \mathrm{g} /$ $\mathrm{mL}$ streptomycin supplemented with $10 \%(\mathrm{v} / \mathrm{v})$ heat-inactivated fetal bovine serum (FBS - Invitrogen, USA).

The photosensitizer used in the preparation of liposomal formulations was a chloro-aluminum phthalocyanine (AlClPc), with maximum absorption at $674 \mathrm{~nm}$. The AlClPc incorporated in liposomal systems of L- $\alpha$-phosphatidylcholine at a concentration of $0.70 \mathrm{mmol} / \mathrm{L}$ was prepared by the injection method with modifications. An ethanolic solution of $0.390 \mathrm{~mL}$ containing $2.61 \mathrm{mg}$ of L-a-phosphatidylcholine $(0.70 \mathrm{mmol} / \mathrm{L})$ was prepared, and an appropriate volume of drug
(AlClPc in ethanol) was added for a final concentration of $5.0 \mathrm{mM}$. A controlled peristaltic pump injected it, in addition to a phosphate buffer saline ( $\mathrm{pH}$ 7.4) contained in a thermostatic jacket (final volume 5.0 $\mathrm{mL}$ ). The buffer solution was kept in a cylindrical container $2.0 \mathrm{~cm}$ in diameter, and the injection was performed below the liquid surface. The injection was performed at $57^{\circ} \mathrm{C}$, which corresponds to the transition temperature of the lipid, under magnetic stirring in the dark and at a rate of $1.0 \mathrm{~mL} / \mathrm{sec}(360 \mathrm{~mL} / \mathrm{h})$.

Dark toxicity of liposomal AlCIPc: 4T1 cells were seeded on 96well plates at a density of $7 \times 10^{3}$ cells/ culture well. Cells were incubated with different concentrations $(5 \mu \mathrm{M}, 2.5 \mu \mathrm{M}, 1.25 \mu \mathrm{M}, 0.625 \mu \mathrm{M}$ and $0.315 \mu \mathrm{M})$ of AlClPc entrapped in liposomal formulation and diluted in DMEM without phenol red for $24 \mathrm{~h}$. A control group of $4 \mathrm{~T} 1$ cells was also maintained. Then, $15 \mu \mathrm{L}$ of MTT solution $(5 \mathrm{mg} / \mathrm{mL}$ in PBS) was added to each well. After $3 \mathrm{~h}$ of incubation at $37^{\circ} \mathrm{C}$ in $5 \% \mathrm{CO}_{2}$, the culture medium was aspirated and $100 \mu \mathrm{L}$ of dimethyl sulfoxide was added. The absorbance was monitored using a spectrophotometer with a microplate reader at a wavelength of $595 \mathrm{~nm}$ (Bio-Rad, Hercules, CA).

Liposomal AlClPc uptake: 4T1 cells were seeded on 96-well plates at a density of $7 \times 10^{3}$ cells/ culture well. Cells were incubated with liposomal AlClPc at $5 \mu \mathrm{M}$ in culture medium DMEM without phenol red. After 5, 15, 30 and 60 minutes of incubation at $37^{\circ} \mathrm{C}$ and $5 \% \mathrm{CO}_{2}$, the supernatants were collected and the wells washed three times with PBS. To each well $150 \mu \mathrm{L}$ of DMSO was added. The reading fluorescence was performed in spectrofluorimeter Spectramax N5 Molecular Devices. The wavelengths of excitation and emission were 350 and $670 \mathrm{~nm}$ respectively. The percentage of liposomal AlClPc was expressed in function of initial concentration of photosensitizer.

Cellular internalization of liposomal AlClPc: After seeding $1 \times 10^{4}$ cells in 24 -well plates coated with sterile cover slips, $125 \mu \mathrm{L}$ of liposomal $\mathrm{AlClFc}$ at $5 \mu \mathrm{M}$ was added in DMEM without phenol red. Incubation was performed for 30 minutes at $37^{\circ} \mathrm{C}, 5 \% \mathrm{CO}_{2}$. The wells were washed with sterile PBS three times and fixed with $4 \%$ sterile buffered paraformaldehyde for 40 minutes. After fixation, the samples were dehydrated and stained with cellular markers for nucleus (Hoescht, 33 442, Molecular Probes, Invitrogen Excitation: Ultraviolet light. Broadcast: 415-450 nm) and cytoskeleton (Alexa-Fluor 488, Molecular Probes, Invitrogen. Excitation: $495 \mathrm{~nm}$. Emission: $510 \mathrm{~nm}$ ). Immediately after being prepared, the slides were analyzed on SP5 confocal microscope (Leica, Sao Paulo, Brazil). The Smart gain, offset and pinhole parameters were the same for all slides.

In vitro PDT protocol: For PDT, $4 \mathrm{~T} 1$ cells were incubated with liposomal AlClPc in DMEM without phenol red for 30 minutes -at $37^{\circ} \mathrm{C}$ and $5 \% \mathrm{CO}_{2}$. Then, culture medium containing photosensitizer was removed and new DMEM without phenol red with $1 \%$ antibiotic was added. Cells were irradiated for five minutes with $50 \mathrm{~mW}, 670 \mathrm{~nm}$ on a final dose of energy of $4.25 \mathrm{~J} / \mathrm{cm}^{2}$. After treatment, cells were reincubated with DMEM supplemented with $10 \%$ fetal bovine serum and $1 \%$ antibiotic until the experimental times of 6 and $24 \mathrm{~h}$ for the assessments described below.

Cell viability: MTT assay was performed in 96-well plates in initial cellular density of $7 \times 10^{3}$ cells/ culture well to assess mitochondrial metabolism of both 4T1 Control and PDT cells. Six and $24 \mathrm{~h}$ after the end of treatment, $15 \mu \mathrm{L}$ of MTT solution $(5 \mathrm{mg} / \mathrm{mL}$ in PBS) was added to each well. After $3 \mathrm{~h}$ of incubation at $37^{\circ} \mathrm{C}$ in $5 \% \mathrm{CO}_{2}$, the culture medium was aspirated and $100 \mu \mathrm{L}$ of dimethyl sulfoxide was added. The absorbance was monitored using a spectrophotometer with a microplate reader at a wavelength of $595 \mathrm{~nm}$ (Bio-Rad, Hercules, CA). 
Citation: Mijan MC, Longo JPF, Melo LND, Simioni AR, Tedesco AC, et al. (2014) Vascular Shutdown and Pro-inflammatory Cytokine Expression in Breast Cancer Tumors after Photodynamic Therapy Mediated by Nano-sized Liposomes Containing Aluminium-Chloride-Phthalocyanine. J Nanomed Nanotechnol 5: 218. doi: 10.4172/2157-7439.1000218

Page 3 of 9

Cell morphology: The morphological evaluation was performed in 96-well plates in initial cellular density of $7 \times 10^{3}$ cells/ culture well. After 6 and $24 \mathrm{~h}$ of treatment, cells were analyzed under contrast phase microscope (Zeiss Axioskop, Germany II). Photomicrographies were captured using Motic Image Plus 2.0 (Motic China Group CO., LTD., Ltd). The following aspects were qualitatively assessed: cellular density, cellular volume, presence of nuclear condensation, adhesiveness to the plate and to surrounding cells, as well as the presence of cellular debris.

Flow-Cytometry analysis: In order to analyze DNA fragmentation and phosphatidylserine A exposure, cells underwent a flow cytometry Annexin V/FITC assay. The flow cytometry analysis was performed in 12 -well plates in initial cellular density of $6 \times 10^{4}$ cells/ culture well. Six and $24 \mathrm{~h}$ after the end of treatment, cells were washed with PBS and resuspended in $100 \mu \mathrm{L}$ binding buffer [ $10 \mathrm{mM}$ HEPES/NaOH ( $\mathrm{pH}$ 7.4), $140 \mathrm{mM} \mathrm{NaCl}, 2.5 \mathrm{mM} \mathrm{CaCl}_{2}$ ]. Five microliters of Annexin-V FITC (Biosource, USA) were added and incubated for $15 \mathrm{~min}$ in the dark at room temperature. At this step, propidium iodide at a concentration of $5 \mu \mathrm{g} / \mathrm{mL}$ was added. The cells were analyzed using a FlowMax flow cytometer and a total of 10,000 events were collected per sample.

\section{In vivo study}

Animal model and tumor induction: Balb /c female mice, aged between 7 and 10 weeks and weighing approximately 20-25 g were used. The animals were purchased from the Central Animal Facility of Goiânia, at the Federal University of Goiânia -(UFG). The mice were kept in cages with controlled temperature $\left(23-24^{\circ} \mathrm{C}\right)$, automated circadian cycle and air filtration. The water and feeding were ad libitum. The research was approved by the ethics committee on animal research at the University of Brasilia (UNB).

$4 \mathrm{~T} 1$ cells were inoculated in the left flank region of the female Balb/c mice. Under general anesthesia with Ketamine $80 \mathrm{mg} / \mathrm{kg}$ and Xylazine $10 \mathrm{mg} / \mathrm{kg}, 50 \mu \mathrm{L}$ of DMEM culture medium without supplementation containing $2 \times 10^{4}$ cells was injected subcutaneously. The mice were evaluated daily. After tumors reached a volume of $70-100 \mathrm{~mm}^{3}$ the treatment and analysis were initiated. The experimental groups were divided into Tumor animals (tumor induction, without treatment, $\mathrm{n}=10$ ) and PDT animals (tumor induction, with PDT mediated with liposomal $\mathrm{AlClFc}, \mathrm{n}=20$ ). A control group with animals without tumors was included for cytokine analyses.

PDT protocol: After tumor growth, the mice underwent general anesthesia with ketamine $80 \mathrm{mg} / \mathrm{kg}$ and xylazine $10 \mathrm{mg} / \mathrm{kg}$. The therapeutic regime employed consisted of peritumoral injection of liposomal AlClPc at $10 \mathrm{mg} / \mathrm{kg}$. After 15 minutes the tumor was irradiated at $670 \mathrm{~nm}, 50 \mathrm{~mW}$ and total irradiation dose was $72 \mathrm{~J} /$ $\mathrm{cm}^{2}$. This regimen was performed three times with a 72-hour interval between sessions.

In vivo and histophatological analysis: Tumor volume was determined as $($ Length $) \times\left(\right.$ width $\left.^{2}\right) \times 0.5$, previously described [20]. The values were measured before each treatment session and before mice were euthanized. Comparison within the experimental groups was performed by variation in tumor volume. The body weight of the mice was also measured during the experimental time interval.

Twenty-four hours after the last PDT session, the animals in the Tumor and PDT groups underwent euthanasia. Tumors were collected for histopathological analysis (each group, $n=5$ ). Tissues were dissected and fixed in buffered paraformaldehyde $4 \%$ solution at room temperature for $2 \mathrm{~h}$. After that, samples underwent histological processing in Histo-Tec DM-20 (Oma, Sao Paulo, Brazil). Tissues were embedded in paraplast and histological sections were performed in ultra-microtome RM2125RT (Leica, Sao Paulo, Brazil) with $5 \mu \mathrm{M}$ thickness. The slides were stained with hematoxylin and eosin (H \& E), and analyses were performed by an optical microscope (Zeiss Axioskop II, Germany). Photomicrographs were captured with a Motic Image Plus 2.0 computer program (Motic China Group CO., Ltd).

Cytokine expression: Six, 24 and 72 hours after the end of the therapeutic regimen, the animals were anesthetized, euthanized, and tumors and plasma were collected and frozen at $-80^{\circ} \mathrm{C}$ for later analysis. The homogenization of tumor tissues was performed with a mechanical homogenizer in pellet buffer homogenate $(300 \mathrm{mM}$ sucrose; $100 \mathrm{mM}$ EDTA; $0.3 \%$ Triton X-100; $1 \mathrm{M} \mathrm{KH}_{2} \mathrm{PO}_{4} ; 20 \mathrm{mM}$ Tris; cocktail of inhibitors protease - Roche; $\mathrm{pH}$ 7.4) on ice. The samples were centrifuged at $10000 \mathrm{rpm}$ for 20 minutes and the supernatant collected for dosage of protein and cytokine analysis. Blood samples $(1 \mathrm{~mL})$ collected by cardiac puncture were centrifuged with the same parameter to collect the supernatant plasma. The dosage of proteins of tumor tissue and plasma was performed by Bradford method. The cytokines in tumors and plasma were expressed in pg / $\mathrm{mg}$ protein. After processing the samples, the analysis of cytokines IL-10, IL-6, IL$1 \beta$, TNF- $\alpha$ and TGF- $\beta$ was carried out using ELISA kits (e-Bioscience and BD, United States).

Statistical analysis: All values were expressed as mean \pm SD. The differences were analyzed by ANOVA and Tukey's post hoc test. The values that were significantly different between groups at $\mathrm{p}<0.05$ were indicated in the figures by an asterisk.

\section{Results}

\section{In vitro}

Figure 1 describes a model of the liposome used in this article. The model represents the spherical nano-vesicles composed by a phospholipid bilayer (Figure 1A). This organization produces a hydrophilic aqueous inner compartment and a hydrophobic compartment among fatty acids chains in the phospholipid bilayer, where AlClPc, as an hydrophobic molecule, is placed. The chemical structure of Aluminium-Chloride-Phthalocyanine is represented in Figure 1.

Dark toxicity of liposomal AlCIPc: As shown in Figure 2A, there was a statistically significant reduction in cell viability for all studied
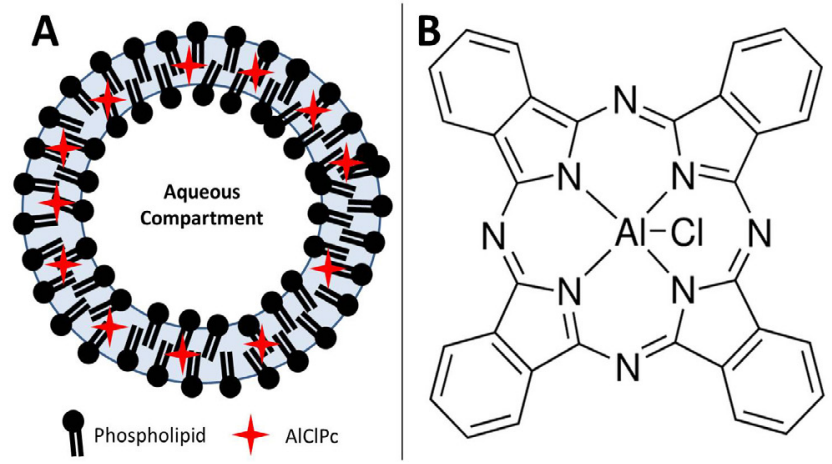

Figure 1: Liposome model containing the Aluminium-Chloride-Phthalocyanine (AICIPC) among the phospholipid bilayer (Section A); Chemical Structure of AICIPc (Sigma-Aldrich) (Section B). 
Citation: Mijan MC, Longo JPF, Melo LND, Simioni AR, Tedesco AC, et al. (2014) Vascular Shutdown and Pro-inflammatory Cytokine Expression in Breast Cancer Tumors after Photodynamic Therapy Mediated by Nano-sized Liposomes Containing Aluminium-Chloride-Phthalocyanine. J Nanomed Nanotechnol 5: 218. doi: 10.4172/2157-7439.1000218
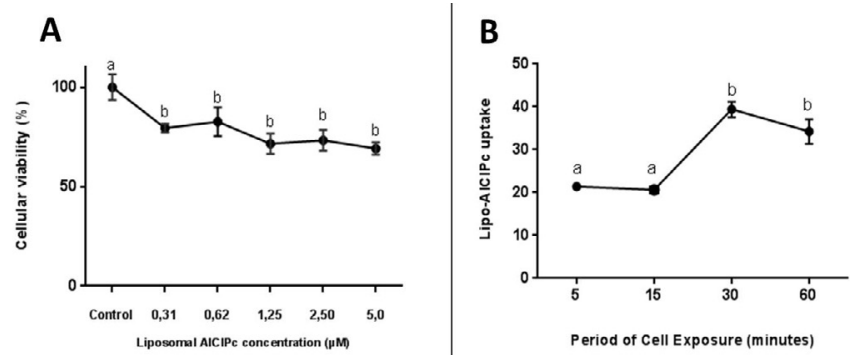

Figure 2: Dark toxicity (Section A) evaluated after 24 hours of Lipo-AICIPc exposure with different AICIPc concentrations; and Lipo-AICIPc cellular uptake (Section B) evaluated with the $5 \mu \mathrm{M}$ AICIPc liposome concentration after different exposure periodos. Letter bindicates significant differences $(p<0.05)$ compared to control.
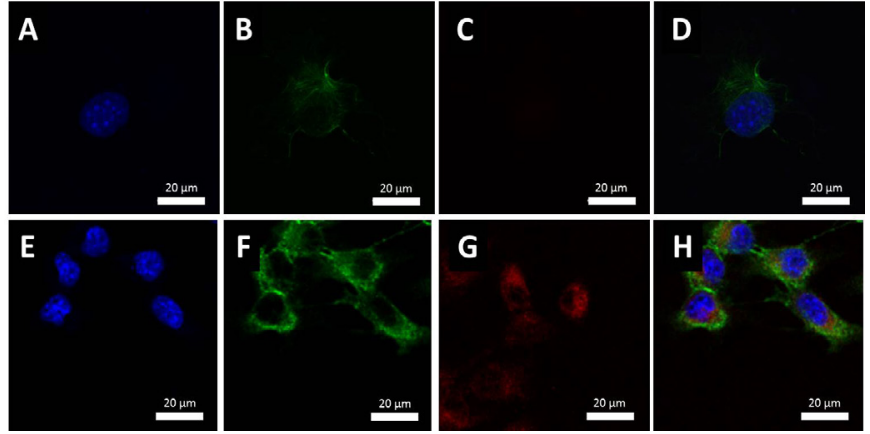

Figure 3: Confocal fluorescent photomicroscopy of control 4T1 cells (Sections A, B, C, D); and Lipo-AICIPc $(5 \mu \mathrm{M})$ (red fluorescence) cellular uptake after 30 minutes of dark exposure (E, F, G, H). Subsections A/E; B/F; C/G; D/H represent, respectively, nuclear staining (Hoescht - blue fluorescent); actin filament staining (Alexa - green fluorescent); AICIPc (red fluorescent); and overlap of the previous fluorescences.

concentrations when compared to cells from the Control group. The reduction in cell viability ranged from $20 \%$ for concentrations of 0.31 and $0.62 \mu \mathrm{M}$ to $35 \%$ for the highest concentration studied $-5 \mu \mathrm{M}$.

Liposomal AlClPc uptake: The uptake peak of liposomal AlClPc in $4 \mathrm{~T} 1$ cells was observed after 30 minutes of incubation. At this time, the internalization was observed of $40 \%$ of the estimated initial concentration of liposomal AlClPc, as shown in Figure 2B. This peak was statistically significant when compared to values of 20 and $21 \%$ found respectively after 5 and 15 minutes of incubation. A fall in internalization was noted after 60 minutes to approximately $34 \%$, and although this was not statistically significant in relation to 30 minutes, it was statistically higher in relation to the two initial times.

Cellular internalization of liposomal AlClPc: After 30 minutes of incubation of liposomal AlClPc in $4 \mathrm{~T} 1$ cells, high photosensitizing accumulation was observed inside cells, as can be seen in Figure 3. It was possible to note drug diffusion across cytoplasmic extension. There was a higher concentration of fluorescence in the perinuclear region (Figure $3 \mathrm{G}$ and $\mathrm{H}$; Red Fluorescence), suggesting preferential accumulation in membranes of organelles. There was no nuclear photosensitizing accumulation. No morphological damage was observed in the cytoplasm, which remained intact, in nuclear conformation, with evident nucleoli.

Cytotoxicity assays: In the PDT group, there was a drastic reduction in cell metabolic activity in both experimental periods of 6 and 24 hours post treatment, with rates of $89.96 \%$ and $92.72 \%$, respectively (Figure 4A). These values were statistically significant compared to the viability observed in Control cells. In Figure $4 \mathrm{~B}$ at $6 \mathrm{~h}$ as well as $24 \mathrm{~h}$ after treatment, $4 \mathrm{~T} 1$ cells were analyzed by flow cytometry. PDT cells were doubly labeled with both annexin $\mathrm{V}$ and propidium iodide, showing, therefore, more than $60 \%$ of double staining (annexin $\mathrm{V} /$ propidium iodide) at both experimental times. This result is statistically significant compared to the Control cells, which presented less than $0.5 \%$ of labeling.

Figure 4C and 4D shows the morphological characterization of cells from both Control and PDT treated cells, respectively. The PDT group presented a reduction in cellular volume, initial loss of adhesion to the surface of the plate and also with other cells, compared to Control cells at $6 \mathrm{~h}$ after treatment. After $24 \mathrm{~h}$, the difference in the cell density was even more evident. The cells of Control remained strongly bonded to the culture plate and also to each other. In contrast, the photomicrograph of cells of PDT showed cell death in a considerable number, resulting in a significant reduction in cell density and cell volume, total loss of adhesion and contact between cells, the presence of cellular debris, roughness in the cytoplasmic membrane and nuclear fragmentation.

\section{In vivo}

In vivo analysis: In Tumor mice, there was an increase of approximately $40 \%$ in tumor volume on day 16 and an increase of more than $60 \%$ at 19 days after tumor induction. In contrast, the group of animals treated with PDT mediated with liposomal AlClPc showed an initial reduction, of $7-10 \%$, followed by a small increase in volume after the last treatment session, as shown in Figure 5A. The difference in tumor volume in both Tumor and PDT group was statistically significant after day 16 . No difference in body weight from the three experimental groups was observed during the experimental period (Figure 5B).

After tumor dissection, there was an evident anti-vascular effect promoted by PDT-mediated AlClPc in liposomal formulation. In Figure
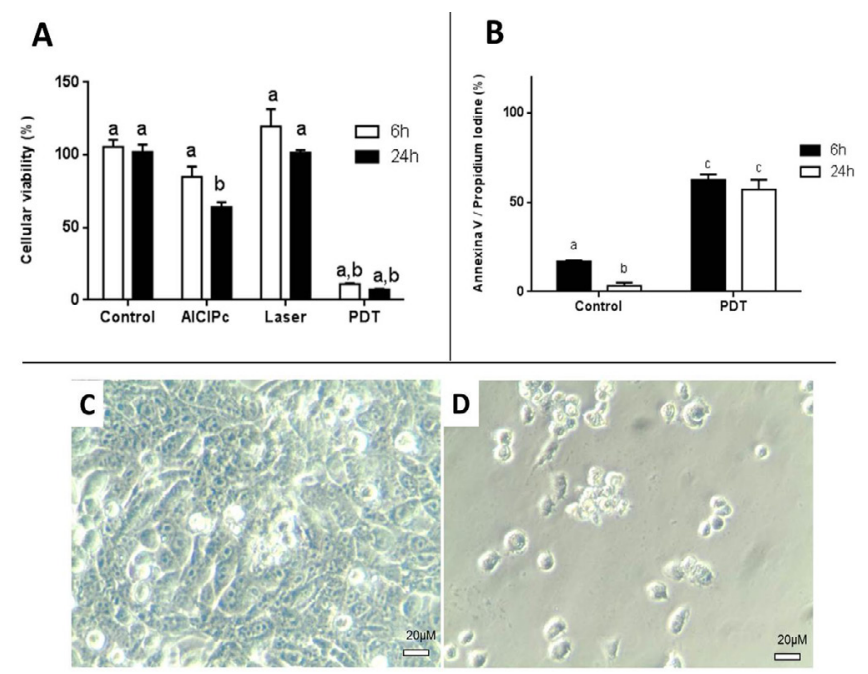

Figure 4: Cell cytotoxicity of PDT mediated by Lipo-AICIPc. Section A represents 4 T1 cell viability evaluated by MTT assay submitted to different treatments after 6 and 24 hours. Section B represents Double staining (Anexin V/Propidium lodine) of 4T1 cells after different treatment after 6 and 24 hours. Letter bindicates significant differences $(p<0.05)$ compared to control. Section $\mathrm{C}$ and D represents, respectively, control and PDT-treated 4T1 cell morphology observed in inverted light microscopy. 
Citation: Mijan MC, Longo JPF, Melo LND, Simioni AR, Tedesco AC, et al. (2014) Vascular Shutdown and Pro-inflammatory Cytokine Expression in Breast Cancer Tumors after Photodynamic Therapy Mediated by Nano-sized Liposomes Containing Aluminium-Chloride-Phthalocyanine. J Nanomed Nanotechnol 5: 218. doi: 10.4172/2157-7439.1000218

A
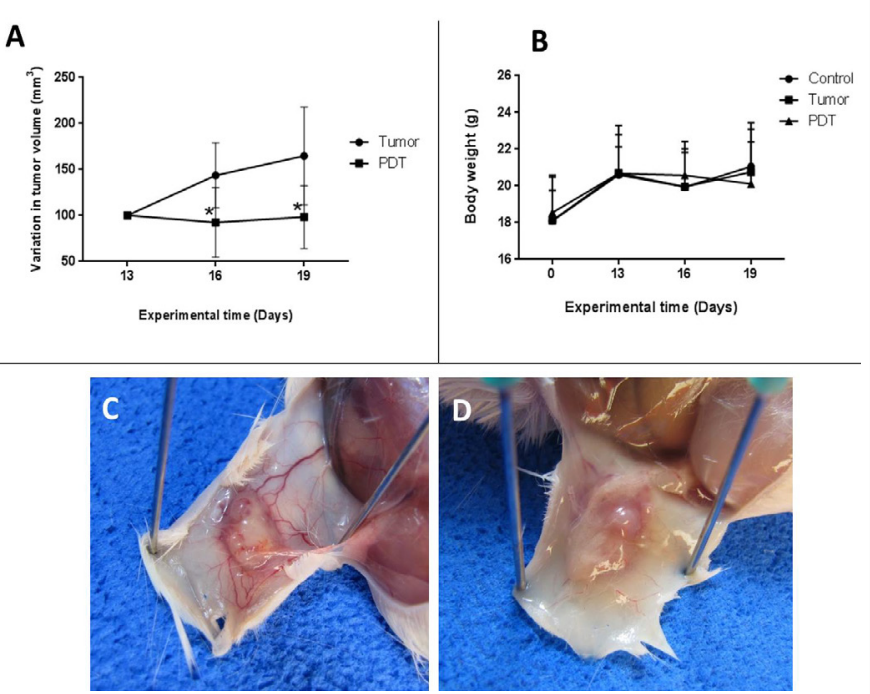

Figure 5: In vivo and Macroscopic alterations observed after PDT in experimental mice. Section A represents relative tumor volume alterations observed during experimental period. Section B represents mice weight variation after different experimental treatments during the experimental period. Sections $C$ and D represent, respectively, control (Day 19) and PDT (Day 19) tumors in a macrosopic view.
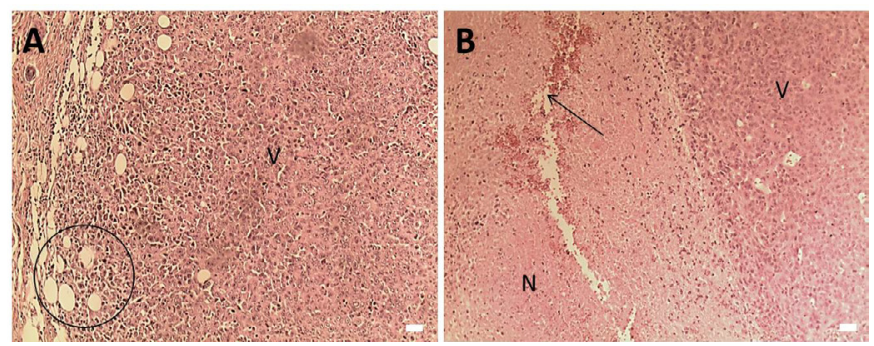

Figure 6: Photomicroscopy of histological sections of untreated control (Section A) and PDT-treated (Section B) tumor. In section A, circle represents viable blood vessels and $V$ representes viable tumor cells. In section $B$, arrow represents damaged blood vessel, and $\mathrm{N}$ represents necrotic tumor tissue. Reference bars represent $40 \mu \mathrm{m}$.

6C and D, the wealth of newly formed vessels in tumors from nontreated animals compared to animals treated with PDT is clearly noted. In the latter, there are clear aspects of vascular ablation, significantly reducing tumor irrigation and nutrition.

Histopathological analysis: Compared to untreated tumors, which had massive tumor cells circumscribed by numerous newly formed blood vessels, in tumors treated by PDT mediated with liposomal AlClPc, there was a clear separation of viable cells from necrotic cells, featuring a central process of coagulative necrosis with large areas of hemorrhage, edema and vascular ablation characterized by the presence of thrombus formation and extravasation of erythrocytes in the whole tumor bed. Vascular shutdown observed in the histopathological analysis corroborate with macroscopic vascular alteration observed in the dissected tumors. In addition to direct cell death observed by induction of necrosis and vascular damage, there were inflammatory infiltrate cells adjacent to necrotic areas, mainly characterized by the presence of neutrophils, as described in Figure 6.

Cytokine expression: Figures 7 and 8 show the cytokine expression in tumor microenvironment of both PDT and un treated Tumor groups, respectively. Local levels of IL-1 $\beta$ in tumor group remained at basal levels of $18.79 \mathrm{pg} / \mathrm{mg}$ protein, while there was an increase in PDT group, which expressed 68.56, 42.45 and $50.08 \mathrm{pg} / \mathrm{mg}$ protein, respectively, after 6,24 and $72 \mathrm{~h}$ after treatment. The values of 6 and 72 hours were statistically significant compared to Tumor group. The same expression pattern was observed in local levels of TNF-a. The PDT group peaked at $122.79 \mathrm{pg} / \mathrm{mg}$ protein 6 hours after treatment, followed by reduction at 24 hours to $37.78 \mathrm{pg} / \mathrm{mg}$ protein and a new increase at 72 hours to $85.09 \mathrm{pg} / \mathrm{mg}$ protein. Compared to Tumor group, whose

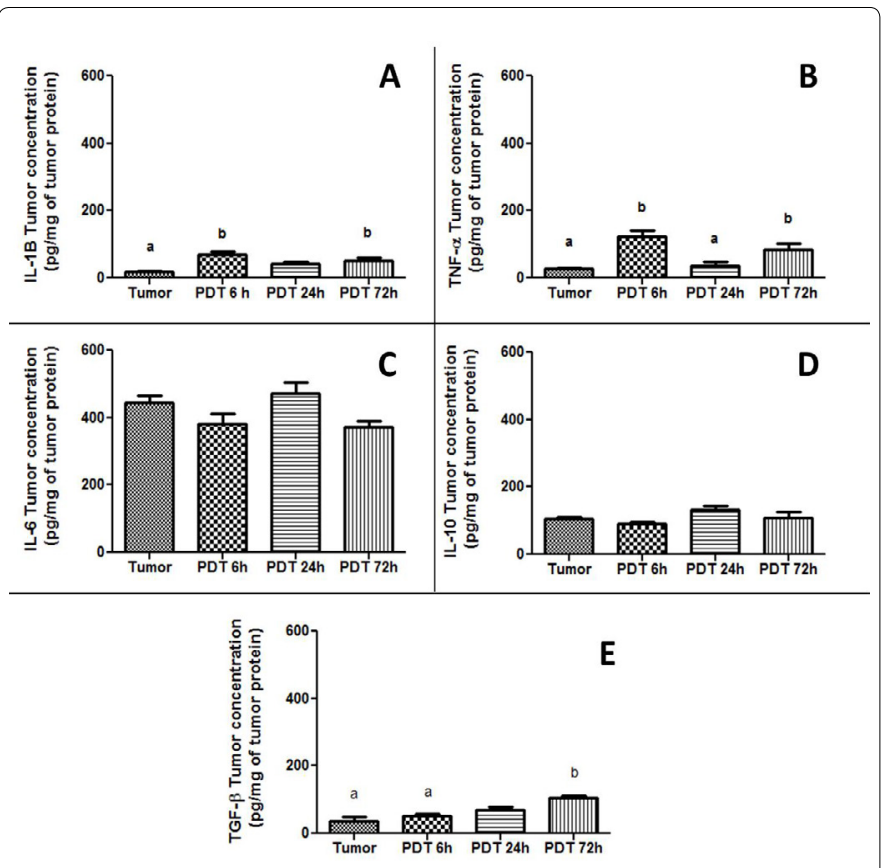

Figure 7: Cytokine expression in tumor tissues. The presence $(\mathrm{pg} / \mathrm{mg}$ Tumor protein) of IL-1B; TNF- $\alpha$; IL-6; IL-10; TGF- $\beta$ in 4T1 tumor tissues after different experimental periods of PDT application are represented, respectively, in sections $A, B, C, D$, and $E$. Letter bindicates significant differences $(p<0.05)$ compared to control.

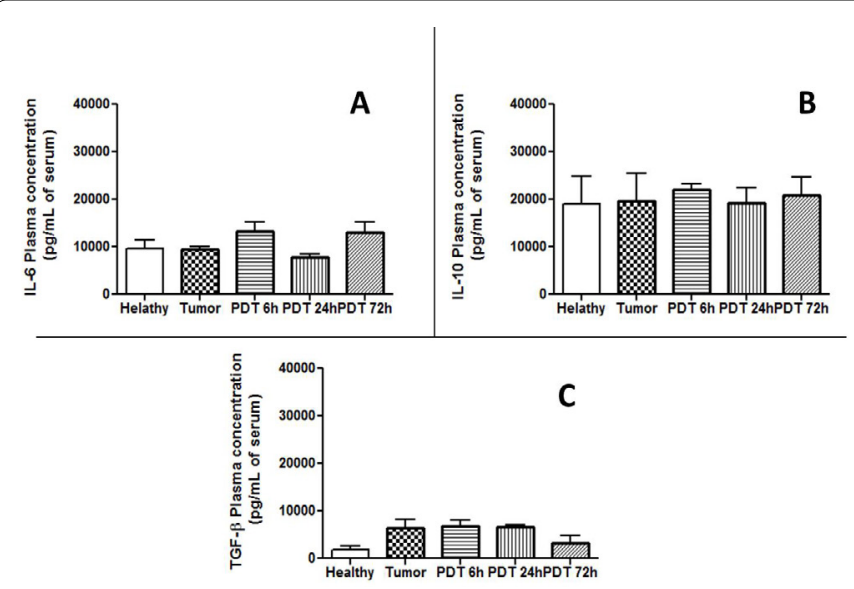

Figure 8: Cytokyne expression in plasma samples. The presence $(\mathrm{pg} / \mathrm{mL}$ of Serum) of IL-6; IL-10; TGF- $\beta$ in plasma samples of 4 T1 tumor-bearing mice after different experimental periods of PDT application are represented, respectively, in sections $A, B$, and $C$. Letter ${ }^{b}$ indicates significant differences $(p<0.05)$ compared to control. 
levels remained at $26.24 \mathrm{pg} / \mathrm{mg}$ protein, the measurements obtained in PDT group at 6 and 72 hours were statistically significant. The serum levels of both IL- $1 \beta$ and TNF- $\alpha$ were undetectable in plasma.

As regards IL-6 expression in tumor tissues, untreated tumor group expressed $444.69 \mathrm{pg} / \mathrm{mg}$ protein of IL-6, while the levels found in PDT group remained at $381.99 \mathrm{pg} / \mathrm{mg}$ protein 6 hours, $471.30 \mathrm{pg} / \mathrm{mg} 24 \mathrm{~h}$ and $373.12 \mathrm{pg} / \mathrm{mg}$ protein $72 \mathrm{~h}$. These patterns were not statistically significantly different from each other. There were no changes in the expression of IL-10. Tumor group ranged from $104.9 \mathrm{pg} / \mathrm{mg}$ protein, while in the PDT group levels were observed of $90.9 \mathrm{pg} / \mathrm{mg}$ protein 6 hours after PDT, $133.23 \mathrm{pg} / \mathrm{mg}$ protein after 24 hours, decreasing again to $107.72 \mathrm{pg} / \mathrm{mg}$ protein at 72 hours. The variations were not statistically significant. Following the same pattern as the local cytokine expression, the systemic expression of IL-6 and IL-10 did not present significant differences among all the experimental groups and time points.

The expression of TGF- $\beta$ changed significantly in animals treated with PDT, especially late in the last session at 72 hours post-treatment. It is possible to observe a gradual increase in TGF- $\beta$ with time after the last session of PDT mediated with liposomal AlClPc. At $72 \mathrm{~h}$ post treatment, the expression of TGF- $\beta$ was $104.52 \mathrm{pg} / \mathrm{mg}$ protein, three times larger than observed in Tumor group, which was $35.23 \mathrm{pg} / \mathrm{mg}$ protein. Intermediately, after $6 \mathrm{~h}$ and $24 \mathrm{~h}$ PDT presented levels of 50.4 and $69.67 \mathrm{pg} / \mathrm{mg}$ protein, respectively. There was a statistically significant difference in TGF-b expression compared to Tumor only in PDT group at $72 \mathrm{~h}$. Despite this significant difference in local expression of TGF-b, the systemic expressions of TGF-b didn't present a significant difference at any of the experimental times.

\section{Discussion}

The effectiveness of PDT against breast cancer and the clinical outcome of this therapy are not agreed on in the literature consensus, and the same applies to skin tumors [21]. However, some singular patterns of PDT, not observed in conventional breast cancer therapies, such as immune system activation, and an increase in immune surveillance against tumor cells may be interesting features for the management and treatment of breast cancer [22]. In addition to that, PDT application can be repeated several times without significant side effects, unlike chemo and radiotherapy, in the management of breast cancer.

The key point of PDT is the photosensitizer (PS) molecule that translates light in ROS production. The Aluminium-ChloridePhtalocyanine (AlClPc) entrapped in nano-sized liposomes is a third generation PS formulation that was previously used in the treatment of different experimental tumor types $[7,18,23]$. The association of PS molecules and nano-carriers has important advantages such as increasing the dispersion of the drugs in aqueous media; increasing the delivery of PS to the tumor tissues and tumor vessels; and preventing drug absorption by normal tissues [24]. Our findings demonstrated that PDT mediated by Lipo-AlClPc was an efficient protocol to control breast cancer cells (4T1) in both in vitro and in vivo experimental models. In addition, the profile inflammatory cytokines expressed after PDT was also assessed in treated animals.

The dark toxicity of Lipo-AlClPc was evaluated after 24 hours of exposure in different PS concentration. All the Lipo-AlClPc concentrations evaluated reduced the $4 \mathrm{~T} 1$ viability, but no significant difference was observed among them. As a strongly hydrophobic molecule, the solubilization of AlClPc in aqueous media is impossible. For that, drug carriers, such as liposomes are fundamental to disperse these molecules in biological aqueous fluids. As the increased concentration of AlClPc didn't' promote higher toxicities, the reduced cell viability may be due to lipids metabolism after liposome uptake. For these reasons, we selected the higher Lipo-AlClPc concentration (5 $\mu \mathrm{M})$ to run the following experiments. These results are in accordance with previous reports with different cell lines [16,23], including a report using a primary canine breast cancer cell line [24] using the same nanosized liposome containing AlClPc. Despite this cell culture cytotoxic effect observed in our results, we have previously showed that this liposome containing AlClPc doesn't have toxicological effects that may affect tumor growth in mice models [17,23].

The Lipo-AlClPc cell kinetics uptake showed that the maximum liposome internalization occurred in 30 minutes, and this value did not increase after one hour of observation. The intracellular delivery of drugs entrapped in liposomes can occur by both endocytic and passive diffusion through the plasmatic membrane pathways [25]. The confocal microscopy confirmed the Lipo-AlClPc uptake by $4 \mathrm{~T} 1$ breast cancer cells, showing that the PS molecules (red fluorescence) were widely dispersed throughout the cytoplasm. This dispersed subcellular localization, as observed by others $[8,26]$, may contribute to drastic cell disruption after PDT, as observed in the cytotoxic assays. ROS produced at different subcellular locations may act together for the cytotoxic effects of PDT. It is important to note in these microscopy analyses that exposure of Lipo-AlClPc in dark conditions did not alter the organization of action filaments, an indication of the harmless pattern of the PS formulation in the dark.

Photoactivation of AlClPc in the PDT treated cells induced significant cell death, up to $90 \%$ at 6 and 24 hours after treatment. In addition, the morphological cell alterations after PDT indicated a strong cytotoxic effect of PDT against the $4 \mathrm{~T} 1$ breast cancer cells. Furthermore, the double staining with annexin $\mathrm{V}$ and propidium iodide indicated a high amount of DNA damage, necrosis, and late apoptosis. This pattern of cell death induced by necrosis and/or late apoptosis was also observed by others $[8,23,27,28]$, and indicates a drastic and unspecific ROS attack on different subcellular regions. As is well known, singlet oxygen produced after PDT has a short half-life and, therefore, a short radius of action $(0.02 \mu \mathrm{m})$ [29], thus producing its effects near to the accumulation site; in our results, PS localization was widely distributed throughout the cytoplasm. Initial apoptosis was not observed in the PDT treated cells. This result may be due to the biochemical machinery requirements needed in the apoptotic pathway, which was probably disrupted after ROS attack on the different subcellular sites after PDT $[27,30]$.

Both necrotic and late apoptosis cell death pathways are characterized by the release of intracellular content into the extracellular media. This subset of molecules, normally protected in intracellular compartments, and released during these types of cell death, is strongly immunogenic and may contribute to the activation of immunological reactions [31], as observed in our anti-tumoral (in vivo) experiments.

Compared to control mice, PDT-treated mice did not present important in vivo side effects during the treatment period. This observation was noted in the weight over time graph, when no significant changes in these two experimental groups were observed. This feature suggests, and was corroborated by others [17,23,32,33], that PDT can be used repeatedly without the significant side-effects that are commonly observed in chemo and radiotherapy and that generally have dose limiting toxicity [34].

The direct cytotoxic effects of PDT were observed in both in vitro and in vivo data, and are due to the oxidative damage to tumor cells 
Citation: Mijan MC, Longo JPF, Melo LND, Simioni AR, Tedesco AC, et al. (2014) Vascular Shutdown and Pro-inflammatory Cytokine Expression in Breast Cancer Tumors after Photodynamic Therapy Mediated by Nano-sized Liposomes Containing Aluminium-Chloride-Phthalocyanine. J Nanomed Nanotechnol 5: 218. doi: 10.4172/2157-7439.1000218

during PDT. Furthermore, a series of macroscopic and microscopic alterations were observed in PDT-treated tumors compared to untreated control tumors. First of all, the volumes of the PDT-treated tumors were significantly reduced compared to the control tumors. This trait was previously observed $[18,26,27]$ and confirms the hypothesis that PDT mediated by Lipo-AlClPc can control tumor growth in animal models. This tumor control may be due to combined effects of the three main biological effects of PDT described previously, which were observed in our results.

Next, PDT-treated tumors presented a clear decrease in the number of viable vessels, a common feature of tissue response against PDT $[18,29,35]$. This vascular shutdown is due to photoactivation of PS in the inner part of vascular structures, resulting in endothelial cell death and consequently in the destruction of vascular structures $[36,37]$. Disruption of vessel integrity contributes significantly to massive tumor necrosis, as observed in the histopathological analysis, after PDT due to hypoxia and nutrient depletion in tumor tissue.

Currently, the direct oxidative damage associated with vascular damage has demonstrated the highest efficiencies of PDT; therefore, vascular targeting is highly desirable in PDT protocols. Dolmans et al. [37] showed that the modulation of the activity of anti-vascular PDT can be obtained by reducing the time interval between application of the photosensitizing drug and light source. With a short time, it was found that the photosensitizer distribution is still incomplete, remaining in the blood stream adjacent to the tumor. Tumor irradiation, therefore, reaches not only the tumor cells themselves, but also the endothelial cells present in the tumor microenvironment [38]. As seen in the present study, the short time interval for tumor light irradiation was effective in vascular ablation.

Moreover, the cellular debris released during tumor necrosis contributes significantly to an immunological activation against the remaining tumor tissues [14]. In addition to that, reduction in vascular supply to the PDT-treated tumor, as presented in our results, can prevent metastatic spread of tumor cells in these vascular pathways. Tamella et al. [39] recently demonstrated that PDT application can shut down tumor-associated vessels, thus preventing tumor cells from disseminating and the establishment of metastatic lesions. In our previous report [15], we demonstrated the inhibition of loco regional metastasis in cervical lymph nodes in a tongue tumor animal model with the same PDT protocol (Lipo-AlClPc) as that used in the present study.

Tumor development is a very complex event that involves the disruption of several tissue and cellular homeostatic patterns during malignant transformation. During tumor development, a series of immunological cells will be present in this microenvironment. Most of them are cells mediating immunosuppression or tolerogenicity that permit tumor progression. In general, the tumor cells are able to produce cytokines creating a vicious circle that maintains this immunosuppressive environment [40]. As an example, expression of TGF- $\beta$, an immunosuppressive cytokine, synthesized mainly by $\mathrm{T}$ lymphocytes and monocytes, and is considered a silent signal to the immune response by inhibiting the differentiation, activation and proliferation of lymphocytes, had a threefold serum increase in tumor-bearing mice compared to healthy mice. The disruption of this immunosuppressive pattern can be achieved by the induction of an immunogenic cell death (necrosis or late apoptosis) [31], such as that observed in our results after PDT application in both in vitro and in vivo experiments. This tumor response after treatment is generally followed by the production and release of several pro-inflammatory cytokines, including IL- $1 \beta$, IL- 6 , TNF- $\alpha$ and IFN- $\Upsilon$, being co-responsible for the induction and maintenance of acute inflammatory response in breast cancer tissues after PDT.

Mroz et al. [27] reported that PDT has a significant effect on the immune system, with both immunostimulatory effects and also immunosuppressive effects [27]. The decision on which immunological pattern will follow is determined largely by the tumor cell death pathway after PDT. These authors [27], and others [14,31], argue that the slight induction of oxidative damage is associated with initial apoptosis pathway, which is related to the release of immunosuppressive cytokines, such as TGF- $\beta$ and IL-10. These cytokines can act to inhibit dendritic cells and also T CD4+ cells. Next, TCD8+ can become anergic and tolerogenic due to the loss of CDT+ activation. Additionally, apoptosis is associated with increased expression of VEGF (vascular endothelial growth factor), which also has immunosuppressive characteristics of inhibiting dendritic cell maturation.

It could be observed in the present study that PDT mediated by local application of Lipo- AlClPc in the treatment of breast cancer in Balb / $\mathrm{c}$ mice acted by multiple mechanisms, contributing to the expression of inflammatory cytokines, resulting in a subsequent anti-tumor inflammatory response. As noted, there is then a significant increase in tumor expression of pro-inflammatory cytokines such as IL-1 $\beta$ and TNF- $\alpha$ in a short period of time after the application of PDT. This proinflammatory ( $\uparrow$ IL-1 $\beta$ / $\uparrow$ TNF- $\alpha$ ) pattern was also observed after 72 hours of PDT application. The increased expression of IL-1b and TNF- $\alpha$ is mainly described as the main effector activation of MHC I structures, associated with an increase in immune recognition and highly desirable in PDT-mediated treatment [41]. Studies in animal models and human models have demonstrated the role of the increase in TNF- $\alpha$ in the induction of innate immune response and consequently the induction of adaptive immune response mediated by effector $\mathrm{T}$ cells, since this molecule has a role both in the maturation of antigen-presenting cells, and maturation of effector T lymphocytes [15]

In contrast to the pro-inflammatory ( $\uparrow$ IL- $1 \beta / \uparrow \mathrm{TNF}-\alpha$ ), TGF- $\beta$ showed a significant increase in expression after 72 hours of PDT application. TGF- $\beta$ is synthesized mainly by $\mathrm{T}$ lymphocytes and monocytes, and is considered a silent signal to the immune response by inhibiting the differentiation, activation and proliferation of lymphocytes [41]. This could be a mechanism involved in returning the immune activation to ground states.

Alternatively, we hypothesized that TGF- $\beta$ hyper-expression after 72 hours of PDT application could be a response to tissue injury. It is well known that TGF- $\beta$ coordinated extracellular matrix remodeling after a different type of tissue damage [42], participating in remodeling necrotic tissue after PDT application. This mechanism has also been observed by other authors after PDT application [43,44]. Furthermore, PDT has been suggested as a strategy to accelerate wound healing, due to these healing properties related to TGF- $\beta$ [45].

From the results obtained in the present article, we can assume that PDT mediated by Lipo-AlClPc acts as an immune stimulating therapeutic modality, given the positive balance between the expression of pro-inflammatory and anti-inflammatory cytokines and silent signals. As discussed previously, most conventional tumor therapies induce an immunosuppression state $[3,4]$. This feature, besides the possibility of repeating the PDT protocol, may be one of the most important proprieties of PDT for cancer treatment. 
Citation: Mijan MC, Longo JPF, Melo LND, Simioni AR, Tedesco AC, et al. (2014) Vascular Shutdown and Pro-inflammatory Cytokine Expression in Breast Cancer Tumors after Photodynamic Therapy Mediated by Nano-sized Liposomes Containing Aluminium-Chloride-Phthalocyanine. J Nanomed Nanotechnol 5: 218. doi: 10.4172/2157-7439.1000218

Therefore, in conclusion, PDT mediated by Lipo-AlClPc is capable of activating all the main mechanisms of PDT described: direct cell damage, induction of vascular shutdown and inflammatory response, providing support to be used at least as an adjunct therapy to surgical treatments, allowing greater tumor control for long periods and, possibly, greater control of metastatic foci.

\section{Acknowledgement}

The authors wish to thank the following Brazilian agencies for their financial support: INCT Nanobiotecnologia-MCT/CNPq, FINEP, CAPES, FAP-DF, and FAPESP (Projects 09/51729-5 and 08-53719-4).

\section{References}

1. Zhu HH, Hu CH, Strickland $P$ (2011) Perspectives of breast cancer etiology: synergistic interaction between smoking and exogenous hormone use. Chin $\mathrm{J}$ Cancer 30: 433-441.

2. Youlden DR, Cramb SM, Dunn NA, Muller JM, Pyke CM, et al. (2012) The descriptive epidemiology of female breast cancer: an international comparison of screening, incidence, survival and mortality. Cancer Epidemiol 36: 237-248.

3. Giuliano AE, Hunt KK, Ballman KV, Beitsch PD, Whitworth PW, et al. (2011) Axillary dissection vs no axillary dissection in women with invasive breast cancer and sentinel node metastasis: a randomized clinical trial. JAMA 305: 569-575

4. DeNardo DG, Brennan DJ, Rexhepaj E, Ruffell B, Shiao SL, et al. (2011) Leukocyte complexity predicts breast cancer survival and functionally regulates response to chemotherapy. Cancer Discov 1: 54-67.

5. Cuenca RE, Allison RR, Sibata C, Downie GH (2004) Breast cancer with chest wall progression: treatment with photodynamic therapy. Ann Surg Oncol 11: 322-327.

6. Mang TS, Allison R, Hewson G, Snider W, Moskowitz R (1997) A phase II/II clinical study of tin ethyl etiopurpurin (Purlytin)-induced photodynamic therapy for the treatment of recurrent cutaneous metastatic breast cancer. The cancer journal from Scientific American 4: 378-384.

7. Rocha MS, Lucci CM, Longo JP, Galera PD, Simioni AR, et al. (2012) Aluminum-chloride-phthalocyanine encapsulated in liposomes: activity against naturally occurring dog breast cancer cells. J Biomed Nanotechnol 8: 251-257.

8. Muehlmann LA, Ma BC, Longo JP, Almeida Santos MF, Azevedo RB (2014) Aluminum-phthalocyanine chloride associated to poly (methyl vinyl ether-comaleic anhydride) nanoparticles as a new third-generation photosensitizer for anticancer photodynamic therapy. Int J Nanomedicine 9: 1199-1213.

9. Portilho FA, Cavalcanti CE, Miranda-Vilela AL, Estevanato LL, Longo JP, et al. (2013) Antitumor activity of photodynamic therapy performed with nanospheres containing zinc-phthalocyanine. J Nanobiotechnology 11: 41.

10. Tong ZS, Miao PT, Liu TT, Jia YS, Liu XD (2012) Enhanced antitumor effects of BPD-MA-mediated photodynamic therapy combined with adriamycin on breast cancer in mice. Acta Pharmacol Sin 33: 1319-1324.

11. Wyss P, Schwarz V, Dobler-Girdziunaite D, Hornung R, Walt H, et al. (2001) Photodynamic therapy of locoregional breast cancer recurrences using a chlorin-type photosensitizer. Int J Cancer 93: 720-724.

12. Castano AP, Demidova TN, Hamblin MR (2004) Mechanisms in photodynamic therapy: part one-photosensitizers, photochemistry and cellular localization Photodiagnosis Photodyn Ther 1: 279-293.

13. Agostinis P, Berg K, Cengel KA, Foster TH, Girotti AW, et al. (2011) Photodynamic therapy of cancer: an update. CA Cancer J Clin 61: 250-281.

14. Castano AP, Mroz P, Hamblin MR (2006) Photodynamic therapy and antitumour immunity. Nat Rev Cancer 6: 535-545.

15. Kick G, Messer G, Goetz A, Plewig G, Kind P (1995) Photodynamic therapy induces expression of interleukin 6 by activation of AP-1 but not NF-kappa B DNA binding. Cancer Res 55: 2373-2379.

16. Tapajós EC, Longo JP, Simioni AR, Lacava ZG, Santos MF, et al. (2008) In vitro photodynamic therapy on human oral keratinocytes using chloroaluminumphthalocyanine. Oral Oncol 44: 1073-1079.

17. Bicalho LS, Longo JP, Cavalcanti CE, Simioni AR, Bocca AL, et al. (2013) Photodynamic therapy leads to complete remission of tongue tumors and inhibits metastases to regional lymph nodes. J Biomed Nanotechnol 9: 811818.
18. Longo JP, Lozzi SP, Simioni AR, Morais PC, Tedesco AC, et al. (2009) Photodynamic therapy with aluminum-chloro-phthalocyanine induces necrosis and vascular damage in mice tongue tumors. J Photochem Photobiol B 94: 143-146.

19. Longo JP, Leal SC, Simioni AR, de Fátima Menezes Almeida-Santos M, Tedesco AC, et al. (2012) Photodynamic therapy disinfection of carious tissue mediated by aluminum-chloride-phthalocyanine entrapped in cationic liposomes: an in vitro and clinical study. Lasers Med Sci 27: 575-584.

20. Schuh JC (2004) Trials, tribulations, and trends in tumor modeling in mice. Toxicol Pathol 32: 53-66.

21. Passos SK, de Souza PE, Soares PK, Eid DR, Primo FL, et al. (2012) Quantitative approach to skin field cancerization using a nanoencapsulated photodynamic therapy agent: a pilot study. Clinical, Cosmetic and Investigational Dermatology 6: 51-59.

22. Allison RR, Sibata C1, Mang TS, Bagnato VS, Downie GH, et al. (2004) Photodynamic therapy for chest wall recurrence from breast cancer. Photodiagnosis Photodyn Ther 1: 157-171.

23. Longo JPF, Melo LND, Mijan MC, Valois CRA, Joanitti GA, et al. (2013) Photodynamic Therapy Mediated by Liposomal ChloroaluminumPhthalocyanine Induces Necrosis in Oral Cancer Cells. Journal of Biomaterials and Tissue Engineering 3: 148-156.

24. Muehlmann LA, Joanitti GA, Silva JR, Longo JP, Azevedo RB (2011) Liposomal photosensitizers: potential platforms for anticancer photodynamic therapy. Braz J Med Biol Res 44: 729-737.

25. Torchilin VP (2005) Recent advances with liposomes as pharmaceutical carriers. Nat Rev Drug Discov 4: 145-160.

26. Hsieh YJ, Wu CC, Chang CJ, Yu JS (2003) Subcellular localization of Photofrin determines the death phenotype of human epidermoid carcinoma A431 cells triggered by photodynamic therapy: When plasma membranes are the main targets. J Cell Physiol 194: 363-375.

27. Mroz P, Yaroslavsky A, Kharkwal GB, Hamblin MR (2011) Cell death pathways in photodynamic therapy of cancer. Cancers (Basel) 3: 2516-2539.

28. Zhou CN (1989) Mechanisms of tumor necrosis induced by photodynamic therapy. J Photochem Photobiol B 3: 299-318.

29. Dolmans DE, Fukumura D, Jain RK (2003) Photodynamic therapy for cancer. Nat Rev Cancer 3: 380-387.

30. Oleinick NL, Morris RL, Belichenko I (2002) The role of apoptosis in response to photodynamic therapy: what, where, why, and how. Photochem Photobiol Sci 1: 1-21.

31. Garg AD, Krysko DV, Vandenabeele P, Agostinis P (2011) DAMPs and PDTmediated photo-oxidative stress: exploring the unknown. Photochem Photobio Sci 10: 670-680.

32. Brown SB, Brown EA, Walker I (2004) The present and future role of photodynamic therapy in cancer treatment. Lancet Oncol 5: 497-508.

33. Hopper C (2000) Photodynamic therapy: a clinical reality in the treatment of cancer. Lancet Oncol 1: 212-219.

34. Curigliano G, Cardinale D, Suter T, Plataniotis G, de Azambuja E, et al (2012) Cardiovascular toxicity induced by chemotherapy, targeted agents and radiotherapy: ESMO Clinical Practice Guidelines. Ann Oncol 23 Suppl 7: 155166.

35. Dougherty TJ (2002) An update on photodynamic therapy applications. J Clin Laser Med Surg 20: 3-7.

36. Castano AP, Demidova TN, Hamblin MR (2005) Mechanisms in photodynamic therapy: Part three-Photosensitizer pharmacokinetics, biodistribution, tumor localization and modes of tumor destruction. Photodiagnosis Photodyn Ther 2: 91-106.

37. Dolmans DE, Kadambi A, Hill JS, Flores KR, Gerber JN, et al. (2002) Targeting tumor vasculature and cancer cells in orthotopic breast tumor by fractionated photosensitizer dosing photodynamic therapy. Cancer Res 62: 4289-4294.

38. Huang Z, Xu H, Meyers AD, Musani Al, Wang L, et al. (2008) Photodynamic therapy for treatment of solid tumors--potential and technical challenges. Technol Cancer Res Treat 7: 309-320.

39. Tammela T, Saaristo A, Holopainen T, Ylä-Herttuala S, Andersson LC, et al. (2011) Photodynamic ablation of lymphatic vessels and intralymphatic cancer cells prevents metastasis. Sci Transl Med 3: 69-69. 
Citation: Mijan MC, Longo JPF, Melo LND, Simioni AR, Tedesco AC, et al. (2014) Vascular Shutdown and Pro-inflammatory Cytokine Expression in Breast Cancer Tumors after Photodynamic Therapy Mediated by Nano-sized Liposomes Containing Aluminium-Chloride-Phthalocyanine. J Nanomed Nanotechnol 5: 218. doi: 10.4172/2157-7439.1000218

40. Garg AD, Agostinis P (2014) ER stress, autophagy and immunogenic cell death in photodynamic therapy-induced anti-cancer immune responses. Photochem Photobiol Sci 13: 474-487.

41. Carpi A, Nicolini A, Antonelli A, Ferrari P, Rossi G (2009) Cytokines in the management of high risk or advanced breast cancer: an update and expectation. Curr Cancer Drug Targets 9: 888-903.

42. Siegel PM, Massagué J (2003) Cytostatic and apoptotic actions of TGF-beta in homeostasis and cancer. Nat Rev Cancer 3: 807-821.
43. Byun JY, Lee GY, Choi HY, Myung KB, Choi YW (2011) The Expressions of TGF-Î' $(1)$ and IL-10 in Cultured Fibroblasts after ALA-IPL Photodynamic Treatment. Ann Dermatol 23: 19-22.

44. Park MY, Sohn S, Lee ES, Kim YC (2010) Photorejuvenation induced by 5-aminolevulinic acid photodynamic therapy in patients with actinic keratosis: a histologic analysis. J Am Acad Dermatol 62: 85-95.

45. Hamblin MR, Hasan T, Trauner K (2000) Acceleration of wound healing by photodynamic therapy US6107466. 